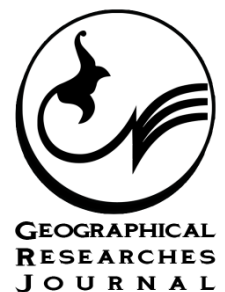

\title{
Barriers to Decision-Making about Water, Food and Energy Resources According to Climate Changes; Applying the Fuzzy Analytic Hierarchy Process Method
}

\section{ART I C L E I N F O}

\section{Article Type}

Original Research

\section{Authors}

Goodarzi MR.*1 $P h D$,

Piryaei R. ${ }^{2} M S c$,

Moosavi MR. ${ }^{2} P h D$

\section{How to cite this article} Goodarzi MR, Piryaei R, Moosavi MR. Barriers to Decision-Making about Water, Food and Energy Resources According to Climate Changes; Applying the Fuzzy Analytic Hierarchy Process Method. Geographical Researches. 2019; 34(3):323-332.
${ }^{1}$ Department of Civil Engineering, Faculty of Civil Engineering, Yazd University, Yazd, Iran

${ }^{2}$ Department of Civil, Faculty of Engineering, Ayatolah Boroujerdi University, Boroujerd, Iran

\section{* Correspondence}

Address: Safaeiyeh, University Boulevard, Yazd University, Yazd, Iran Phone: +98 (35) 31232222 Fax: +98 (35) 38200148 goodarzimr@yazd.ac.ir

\section{Article History}

Received: February 16, 2019

Accepted: August 28, 2019

ePublished: October 2, 2019

\begin{abstract}
A B S T RACT
Introduction and Background The connections (Nexus) among Water, Food and Energy respresent a number of interdisciplinary and multi-sectoral complexities and challenges. Water, Food and Energy resources are affected by climate change. The present study aims at evaluating the impact of climate change on decision making regarding Water, Food and Energy using Fuzzy Analytic Hierarchy Process Method.

Methodology The main purpose of this research is to prioritize decision barriers using multi-criteria decision-making techniques. The purpose of the present study is in the field of applied research. Fuzzy hierarchical analysis technique was used to prioritize the elements. Questionnaires based on paired comparison from the experts' point of view were used for data collection.

Findings The results suggest that water resource is put in the first priority with the normal weight of 0.591 , food with the normal weight of 0.304 , and energy with the normal weight of 0.105 are in the second and third priority respectively. Furthermore, a new approach to the integrated management of sustainable development is recognized as the most important barrier to making decisions on the measures of water, food and energy with the normal weights of $0.256,0.261 \& 0.292$. The last important barriers are identified as cooperation and communication, the nature of response to communicational shocks, and cooperation and communication with the normal weights of $0.069,0.087$ and 0.071 , respectivelly. With respect to the final prioritization, the new approach to the integrated management of sustainable development and the measure of cooperation and communication are acknowledged as the most and least important barriers, respectively, with the normal weights of 0.292 and 0.071 .

Conclusion water, food and energy resource are ranked first, second and third respectively. The most important barrier for decision making regarding water, food and energy was "the new approach for managing and organizing considering sustainable development" and the least important one is "communication and collaboration".
\end{abstract}

Keywords Climate Changes; Barriers to Decision-Making; Fuzzy AHP Hierarchical Method; WaterEnergy-Food Nexus

\section{I T A T I O N L I N KS}

[Audet; 2014] The double hermeneutic of sustainability ...; [Biggs, et al; 2015] Sustainable development and the water-energy ...; [Cai, et al; 2018] Understanding and managing the food-energy ...; [Ely, et al; 2013] Innovation politics post-Rio+20: Hybrid ...; [Endo, et al; 2017] A review of the current state of ...; [Hallegatte, et al; 2015] Shock waves: Managing the impacts ...; [Hoff H; 2011] Understanding the ...; [Howarth \& Monasterolo; 2016] Understanding barriers to decision ...; [Hsiang, et al; 2011] Civil conflicts are associated with ...; [Hussey \& Pittock; 2012] The energy-water nexus: Managing the ... [International Energy Agency; 2011] World energy outlook ...; [Intergovernmental Panel on Climate Change; 2014] Climate change 2014: Synthesis report: Longer ...; [Kahraman \& editor; 2008] Fuzzy multi-criteria decision making: Theory ...; [Kelley, et al; 2015] Climate change in the Fertile ...; [Kurian \& Ardakanian; 2014] Institutional arrangements and ...; [Leach, et al; 2012] Transforming innovation for ...; [Lee, et al; 2011] Population aging and the generational ...; [Meybeck, et al; 2012] Building resilience for adaptation to ...; [Millennium Ecosystem Assessment; 2005] Ecosystems and human well ...; [Münchener Rück Stiftung; 2012] Natural catastrophes 2011: Analyses, ...; [OECD; 2012] OECD environmental outlook to 2050: The ...; [Philip, et al; 2011] Decision making in a changing ...; [Rasul; 2014] Food, water, and energy security in ...; [Rasul \& Sharma; 2016] The nexus approach to waterenergy-food security: An ...; [Rees \& Wackernagel; 1996] Urban ecological footprints: Why ...; [Roberts \& Finnegan; 2013] Building Peace around water, land and food: Policy ...; [Smajgl, et al; 2016] The water-food-energy Nexus-Realising a new ...; [Smith, et al; 2014] Agriculture, forestry and other land ...; [Teng \& Tzeng; 1998] Transportation investment project selection with ...; [The World Economic Forum Water Initiative; 2011] Water security: The water-food-energy ...; [World Bank Group; 2013] Turn down the heat: Climate ...; [World Business Council for Sustainable Development; 2014] Co-optimizing Solutions: Water and ...; [Yumkella \& Yillia; 2015] Framing the water-energy nexus for the ...; 
كنفرانس تهيه كرد كه براساس آن مفهوم آب، غذا و انرزى در جامعه

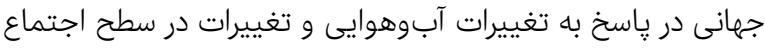

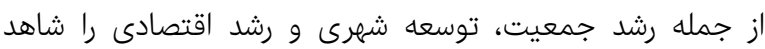

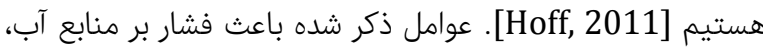

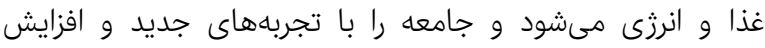

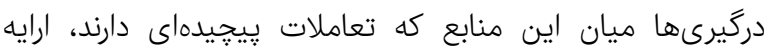

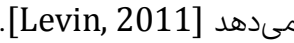

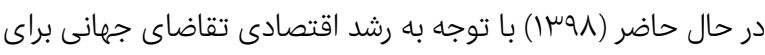

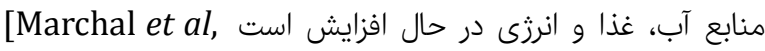

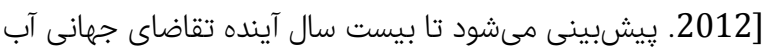

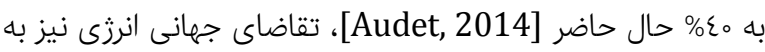

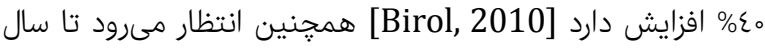

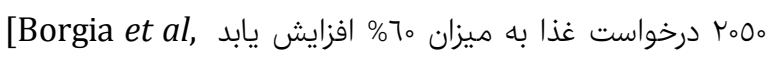

.2014]

شهرها بهطور خاص مصرفكننده بيش از حد منابع طبيعى هستند

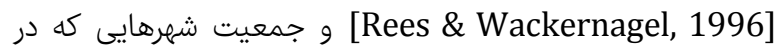

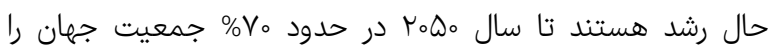
تشكيل خواهند داد [Lee \& Mason, 2011]. الكوى نادرست كنونى بيش از حد مصرف منابع طبيعى باعث شده در آب و هوا تغييرات خطرناكى ايجاد شود [Team et al, 2014]. استفاده بهينه، مناسب و عادلانه از منابع طبيعى براى آينده صلحآميز

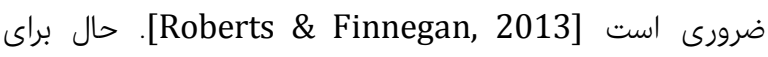

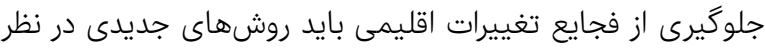

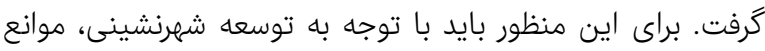

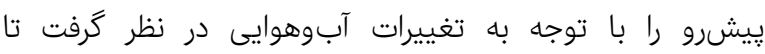
برنامهريزىهاى آتى دقيق و بهطور كامل صورت كَيرند.

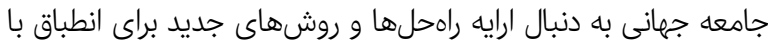

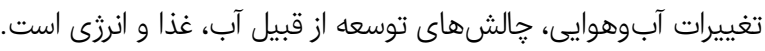

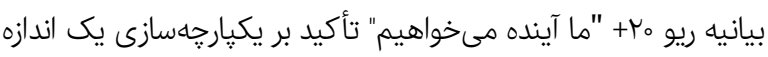

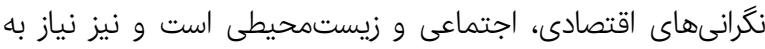

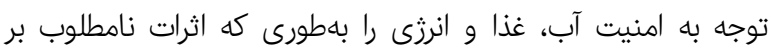

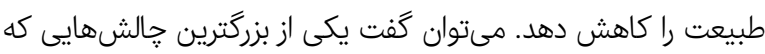

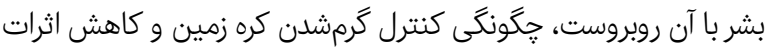

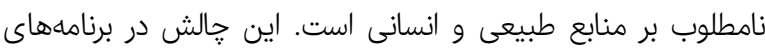

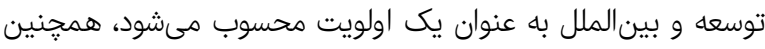

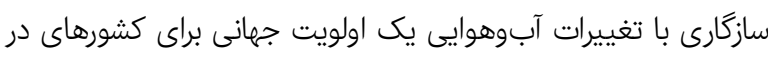

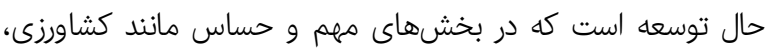
شيلات و غيره ظرفيت محدودى دارند [Levin, 2011] توسعه بايدار

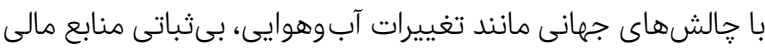

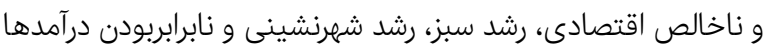

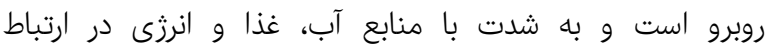

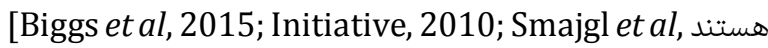

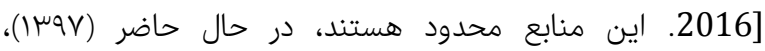
سيستمهاى انسانى مانند سرعت برداشت آب، سريعتر از آنجه است است
موانع تصميمحزيرى در خصوص منابع آب، غذا و انرزى با توجه به تغييرات اقليمى؛ كاربرد روش تحليل سلسله مراتبى فازى

PhD محمدرضا گودرزى كروه عمران، دانشكده عمران، دانشگاه يزد، يزد، ايران MSc رضا بيريايى دان كروه عمران، دانشكده فنى و مهندسى، دانشگاه آيتحاله بروجردى، بروجرد، ايران ميرحيم موسوى ShD گروه عمران، دانشكده فنى و مهندسى، دانشگاه آيتحاله بروجردى، بروجرد، ايران

جكيده

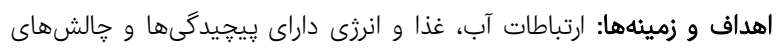

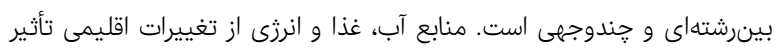

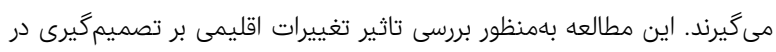

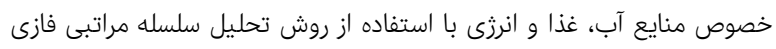
انجام شد.

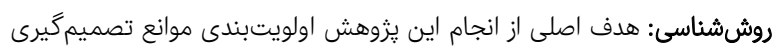

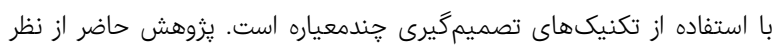

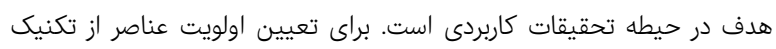

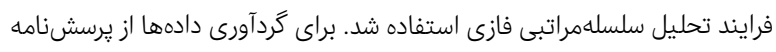

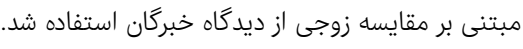

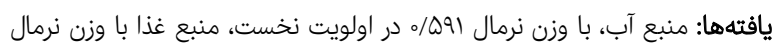

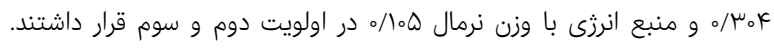

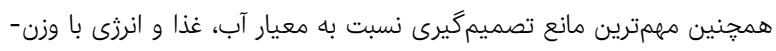

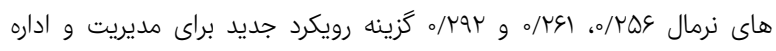

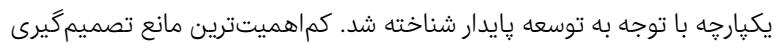

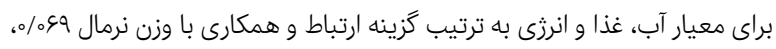

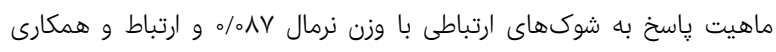

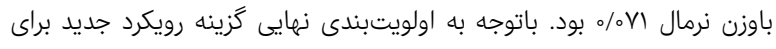

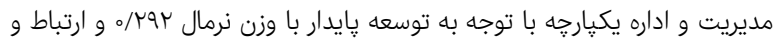

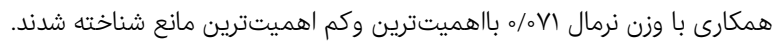

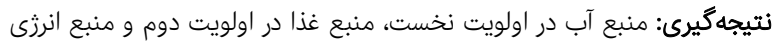

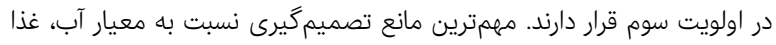

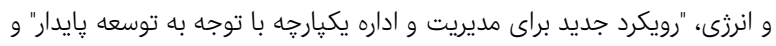

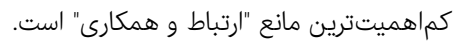

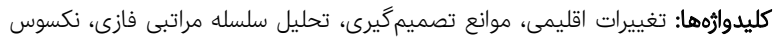

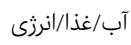

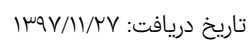

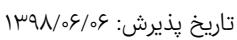

"نويسنده مسئول: goodarzimr@yazd.ac.ir

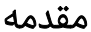

ايده ارتباط آب، غذا و انرزى به صورت جدى از كنفرانس نكسوس

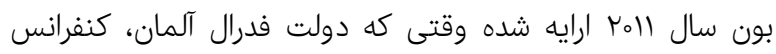

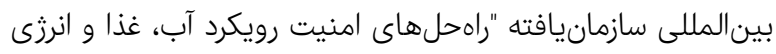

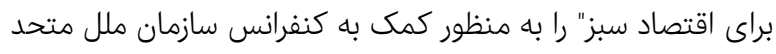

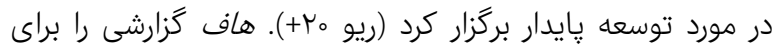




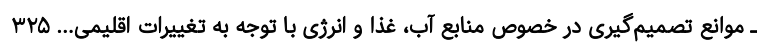
[ \&onasterolo, 2016. اين شوكها در كشورها تأثيرگذار هستند

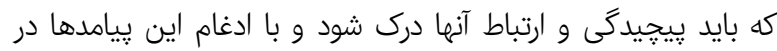

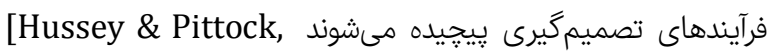

آب، انرزى و امنيت غذايى در سطح جهانى را مىتوان از طريق يك

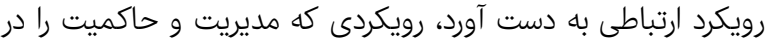

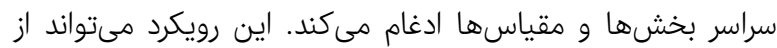

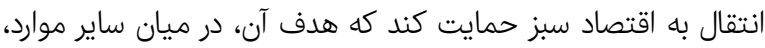
در بهرهورى استفاده از منابع و انسجام سياست بيشتر است. با توجه

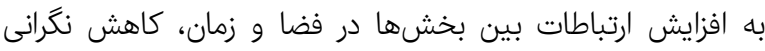

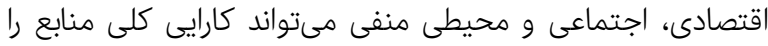

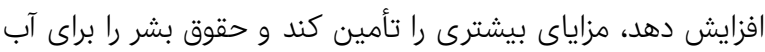

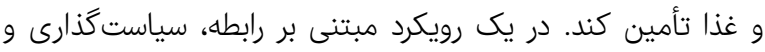

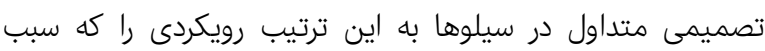

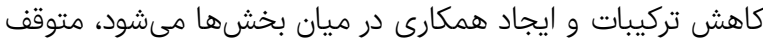
مى كند. اتحاديه ارويا با همكارى وزارت همكارى و توسعه فدرال آلمان و موسسه تحقيقاتى سياست بين المللى غذا، WWF و انجمن جهانى تجارت يك منبع اينترنتى را بر اين نكرانى ايجاد كردهاند

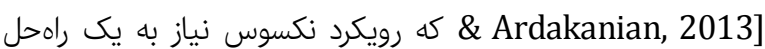

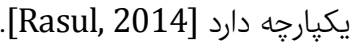
اخيراً در سطح جهانى وقايع فاجعهآميز براى زندگى انسان انسان (مانند سيل و خشكسالى) مشاهده شده است كه امنيت در اين شوكايع فئها

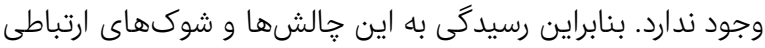

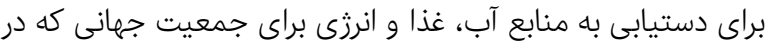

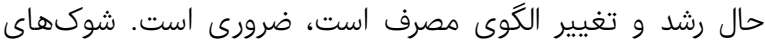

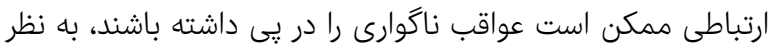

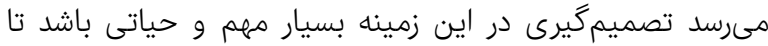

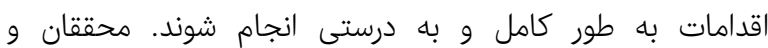
دانشمندان زيادى به بررسى روابط بين منابع آب، غذا و انرزى

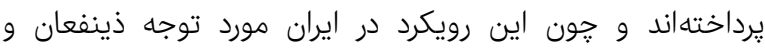

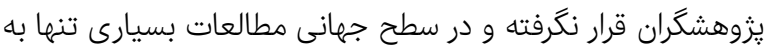

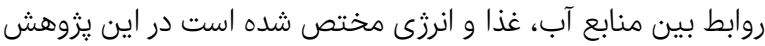

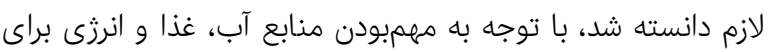

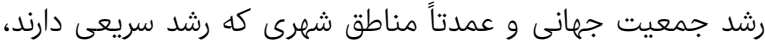
به شناخت موانع تصميمگيرى در زمينه شوكهاى ارتباطى ترداخته شد. اولويتبندى اين موانع به روش تحليل سلسله مراتبى فازى انجام مىشود (Analytic Hierarchy Process; AHP) زيرا استفاده از مجموعههاى فازى، سازگارى بيشترى با توضيحات

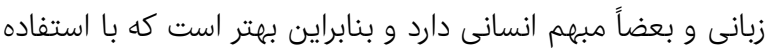

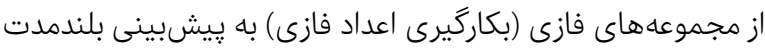

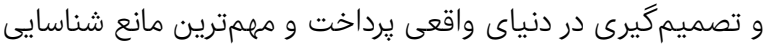

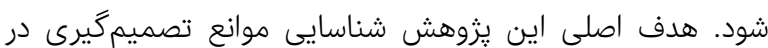

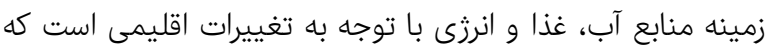

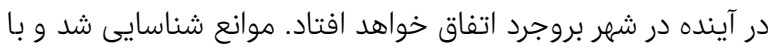

كه مىتوان برداشت كرد [Meybeck et al, 2012]. فعاليتهايىكه توسط انسان صورت مى

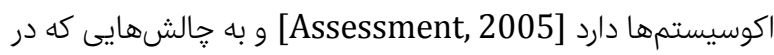
سطح جهان اتفاق مىافتد، مانند تغييرات آبوهوايى كمك مى دوند

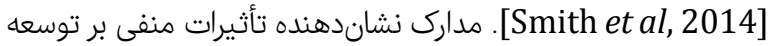

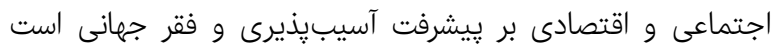
[Schellnhuber et al, 2013]. افزايش عدم قطعيت دئس در مورد امنيت آب و انرزى و نوسانات زياد در قيمت مواد غذايى و انرزى، إنال يديدآورنده خطر نآرامىهاى اجتماعى و بىثباتى در سياست مى نى [Hsiang et al, 2011; Kelley et al, 2015] باعث بالا رفتن هزينههاى اجتماعى و اقتصادى، هزينههاى شوكهاى

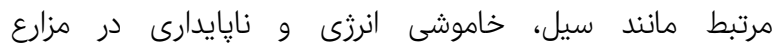

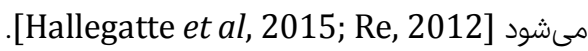
رسول و شارها [Rasul \& Sharma, 2016] در تحقيقى به بررسى

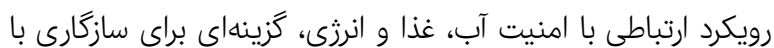
تغييرات اقليمى يرداختند. آنها يافتند كه رويكرد نكسوس (Nexus)

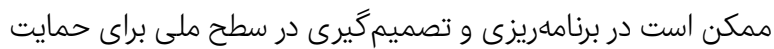

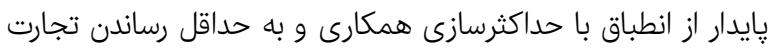

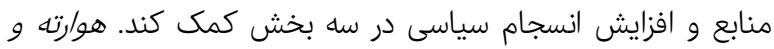
مونسترلو [Howarth \& Monasterolo, 2016] در تحقيقى به إنه بررسى فرصت براى افزايش دانش در رويكرد انرزى، غذا و آب: ايجاد

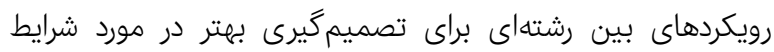

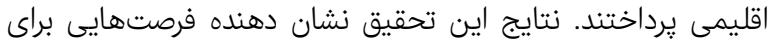

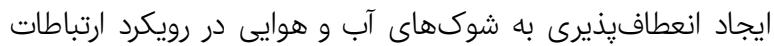
آب، غذا و انرزى بود و همانطور عوامل كه توسط مشاركت كنندكان

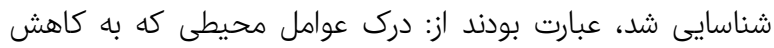

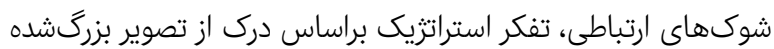

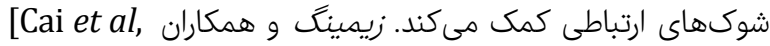
[2018 در تحقيقى به درك و مديريت ارتباطات آب، انرزى و مواد غذايى، فرصت تحقيق در زمينه منابع آب ترداختند. جششم انداز آنها با

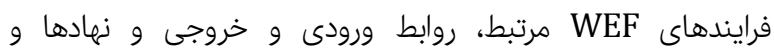
هميوشانى زيرساختها مشخص مىشود. در فرايندها، سيستمها،

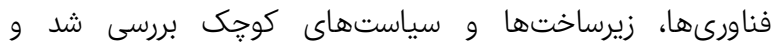

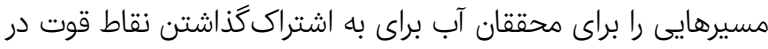
جوامع وسيع WEF در حوزه غذا و انرزى شناسايى كردند

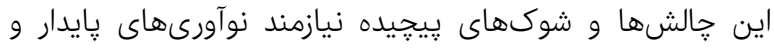
تغييرات است [Ely et al, 2013; Leach et al, 2012]. خطرات و ييامدهاى ناشى از مديريت اشتباه منابع آب، غذا و انرزى، مسايل

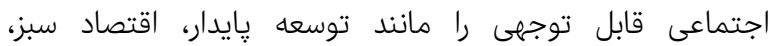
سرمايههاى طبيعى، اداره محيط زيست و خدمات اكوسيستم ايجاد

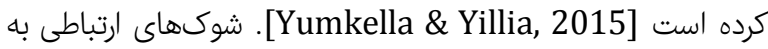

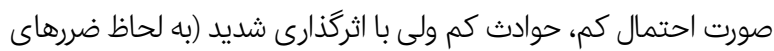

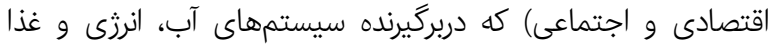

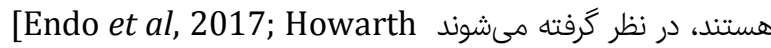


بيشترى با توضيحات زبانى و بعضاً مبهم انسانى دارد و بنابراين

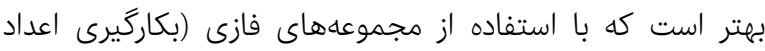

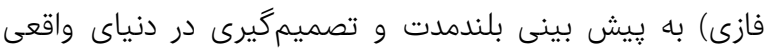

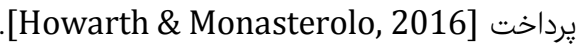

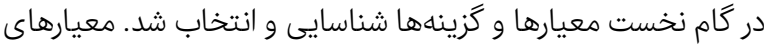

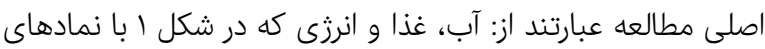

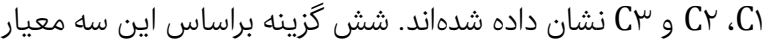

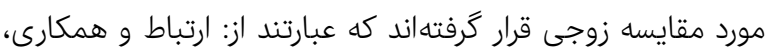

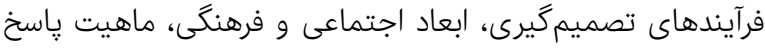

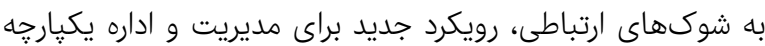

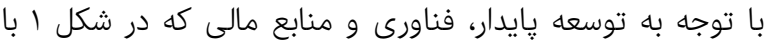

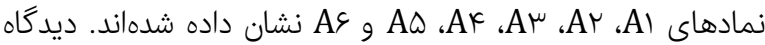
تعدادى از خبركان براى هريك از معيارها و زيرمعيارها كَردآورى شد.

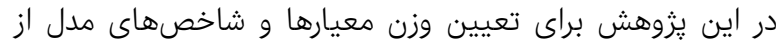

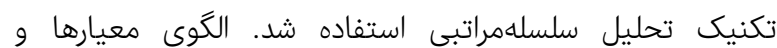
زيرمعيارهاى مدل با استفاده از تكنيك AHP در شكل ؟ ترسيم شد.
روش AHP فازى اولويتبندى شدند تا مهمترين موانع شناسايى و

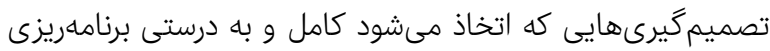

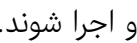

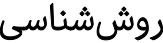

هدف اصلى از انجام اين يزوهش اولويتيتبندى موانع تصميمكيرى

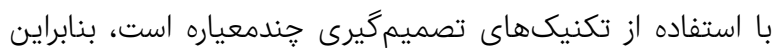

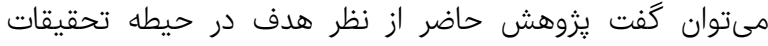

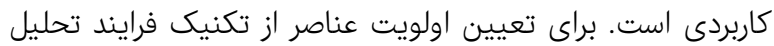

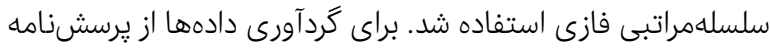

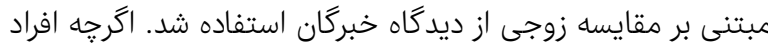

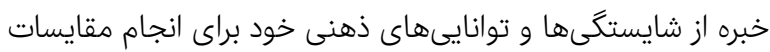

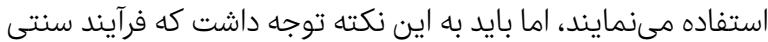

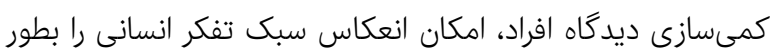
كامل ندارد. به عبارت بهتر، استفاده از مجموعههاى فازى، سازكارى إنى

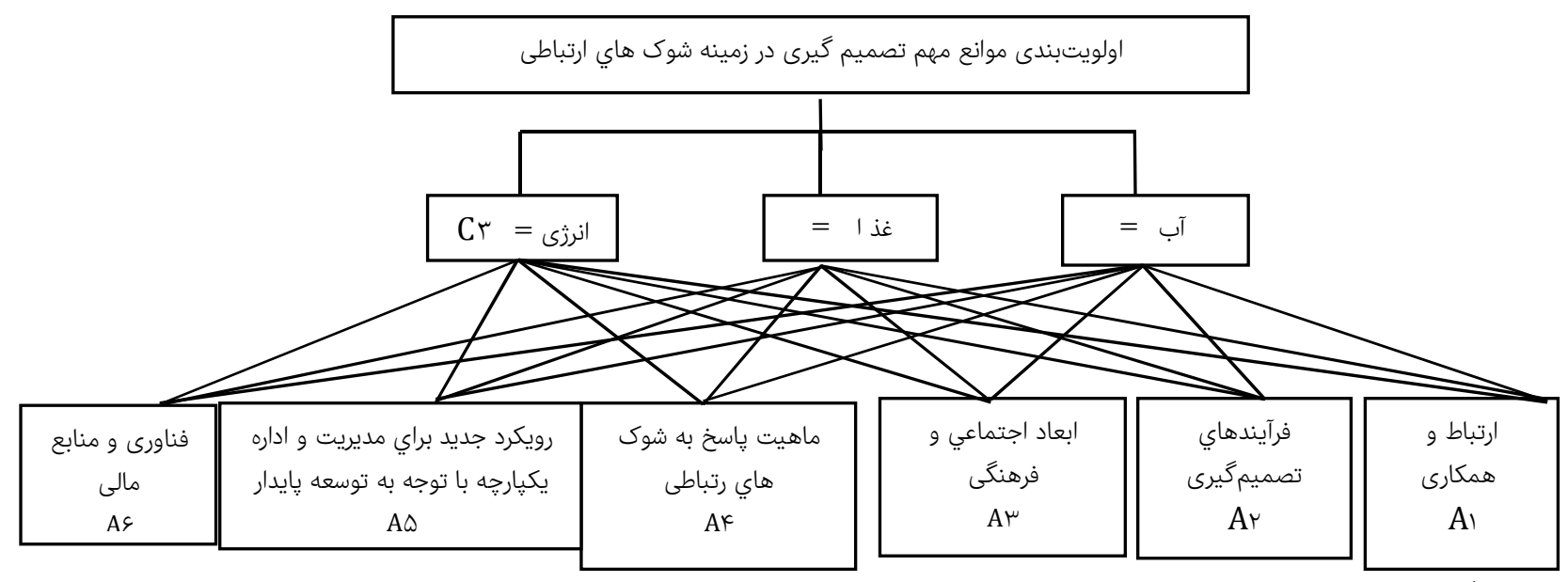

شكل () الكوى سلسلهمراتب يُروهش

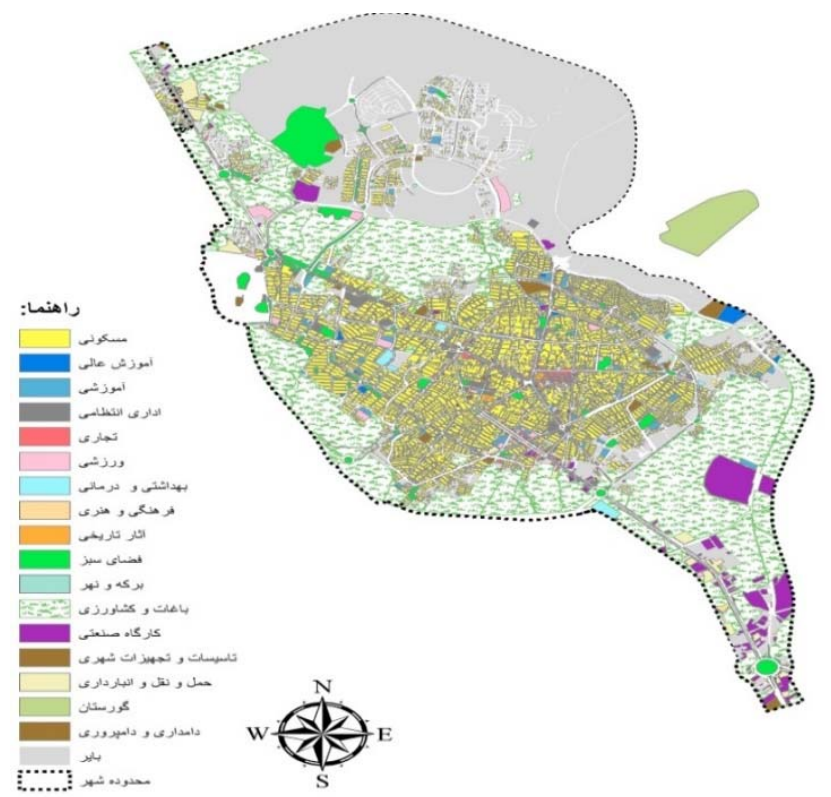

شكل r) نقشه كاربرى شهرستان بروجرد به تفكيك فضاها 


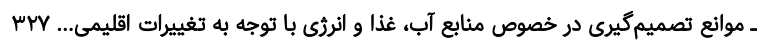

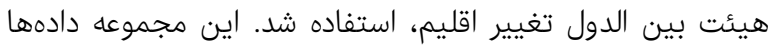
آزادانه از طريق مركز توزيع داده كه توسط IPCC دئن العر سال 1991 شكل

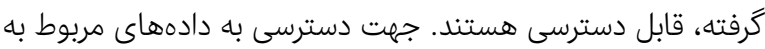

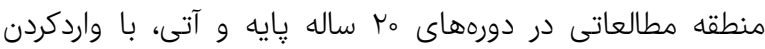

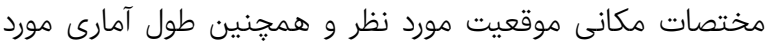

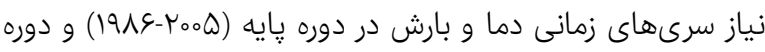

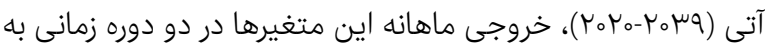

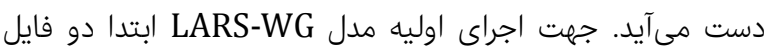

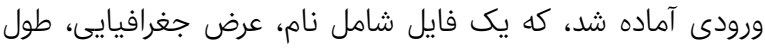

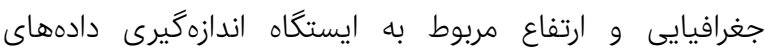
هواشناسى است و فايل ديكر شامل دادههاى هواشناسى ورودى به به إسه

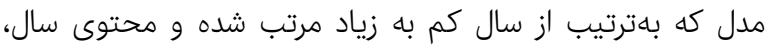
شماره روز، حداقل دما، حداكثر دما، بارش و ساعات آفتابى (دلخواه)

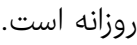

\section{Nيدگاه Nexus}

ديدكًاه ارتباطى، درك وابستگىهاى متقابل در بخشهاى آب، انرزى

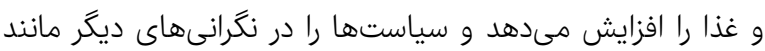

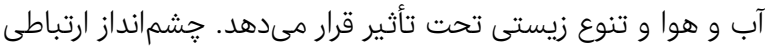
به حركت به جلو از سيلوها و برجهاى عاج كمك مى زئنس تئد كه

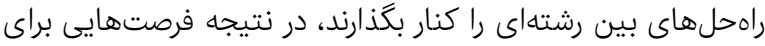

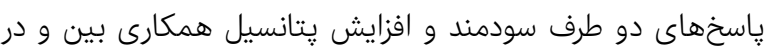

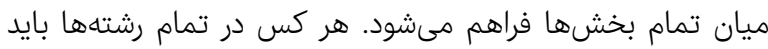

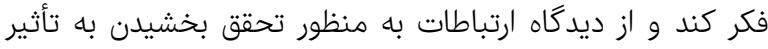

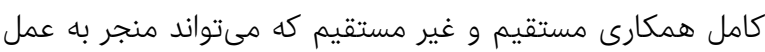

درك عميق از ارتباط، جارجوب آكَاهانه و شفاف را فراهم مىكند كه براى ياسخكويى به افزايش تقاضاى جهانى مى جايدايد، بدون اينكه مانع

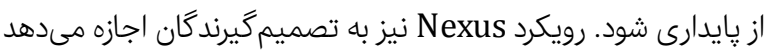

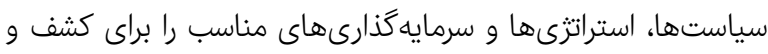

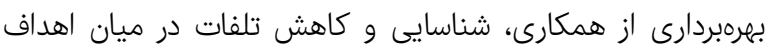

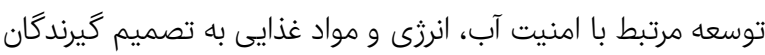

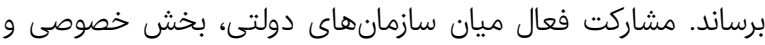

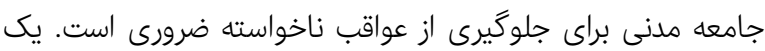

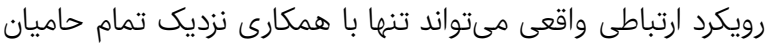

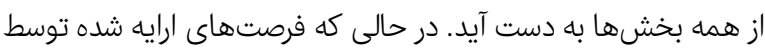

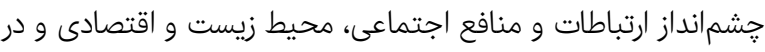

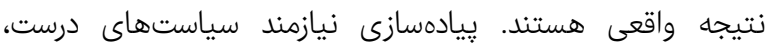

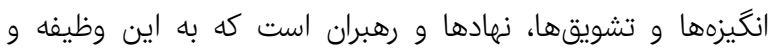
همجنين جارجوبى كه توانمندسازى تحقق اطلاعات را داشته باشده. سرعت بخشيدن به دخالت بخش خصوصى از طريق ايجاد و ترويج

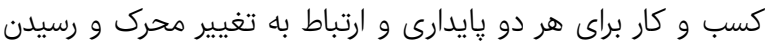

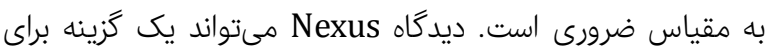

سازگارى با تغييرات اقليمى باشد [Rasul \& Sharma, 2016].
در اين تحقيق براى شناسايى معيارها و كزينهها از ادبيات يزوهش، مطالعات كتابخانهاى و مصاحبههاى تخصصى استفاده شد. براى

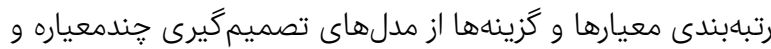

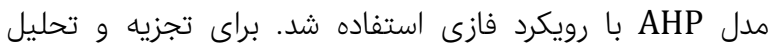

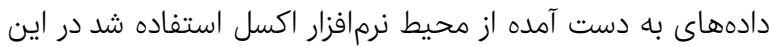

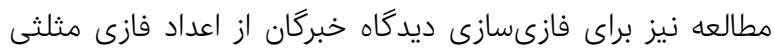

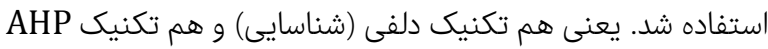

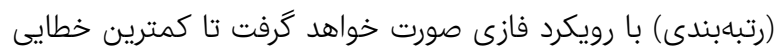
در كار وجود داشته باشد. در اين مطالعه معيارهاى اصلى و عناصر

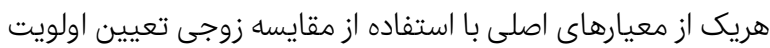
شدهاند. براى اين منظور از طيف نه درجه ساعتى استفاده شده است. روند تحليل به صورت زير است: ا- مقايسه زوجى معيارهاى اصلى براساس هدف و تعيين وزن

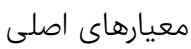
r- مقايسه زوجى گزينهاريا براساس هر مر معيار س- تعيين وزن نهايى ززينهها براى مقايسه زوجى عناصر از مقياس نه درجه ساتى استفاده شد. مقياس نه درجه ساتى توسط توماس ساعتى واضع تئورى تحليل

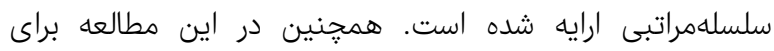

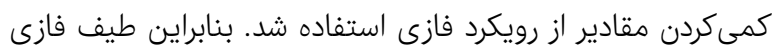
ساعتى مورد استفاده قرار گرفته است.

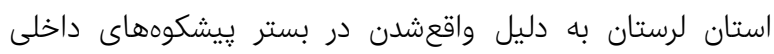

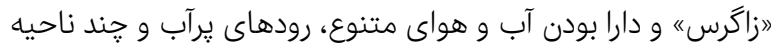

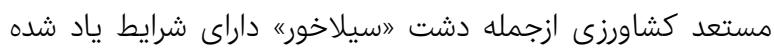

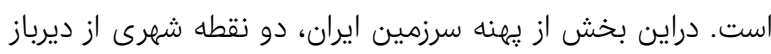

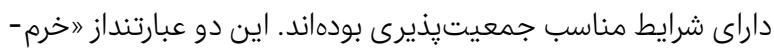

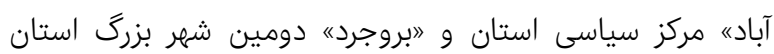
لرستان. شهرستان بروجرد يكى از شهرستانهاى استان لرستان

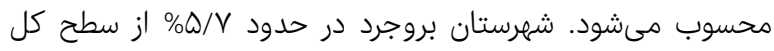

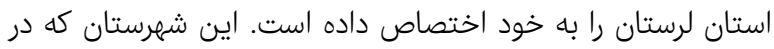

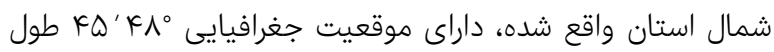

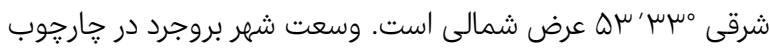

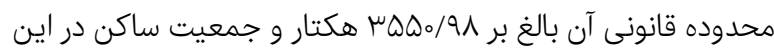

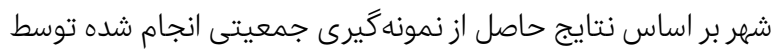

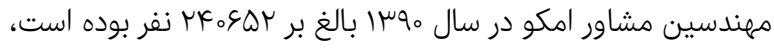

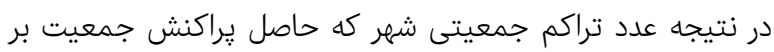

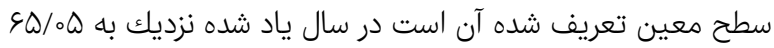

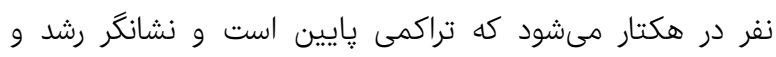

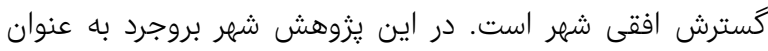
محدوده مطالعاتى مورد استفاده قرار گرفت.

تغيير اقليم در اين بزروهش، از خروجى مدل HADGEM2 تحت دو سناريوى

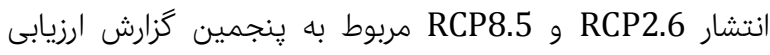


ماتريس مقايسه زوجى X ${ }^{\tilde{X}}$ به صورت نمايش داده مىشود.

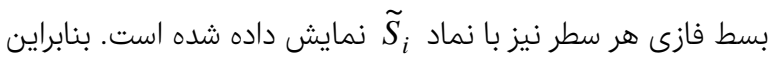

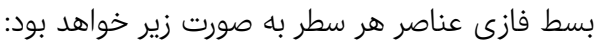

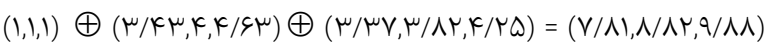

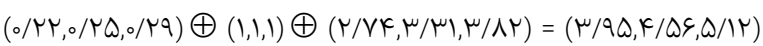

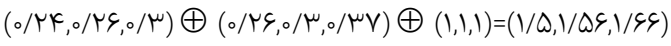
بسط فازى ترجيحات هريك از معيارهاى اصلى به صورت زير خواهد بنابراين براساس رابطه جهارخواهيم داشت: $\tilde{S}_{1}=(\mathrm{V} / \mathrm{\Lambda} \mathrm{I}, \Lambda / \Lambda \mathrm{r}, \mathrm{q} / \mathrm{\Lambda \Lambda})$

$\tilde{S}_{r}=(r / Q \Delta, r / \Delta \xi, 0 / I r)$

$\tilde{S}_{r}=(1 / \Delta, 1 / \Delta \xi, 1 / 77)$

$\left(\sum \tilde{S}_{i}\right)^{-1}=(\cdot 1 \cdot 4, \% \cdot \odot V, \% \vee \vee \Delta)$

نتايج حاصل از نرمالسازى مقادير به دست آمده به صورت زير

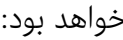

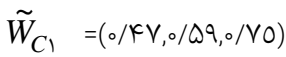

$$
\begin{aligned}
& \tilde{W}_{C r}=(0 / \mu K, 0 / \mu, 0 / \mu q) \\
& \tilde{W}_{C r}=(\% / 09,0 / 1,0 / / \mu)
\end{aligned}
$$

هريك از مقادير به دست آمده وزن فازى و نرمال شده مربوط به معيارهاى اصلى هستند.

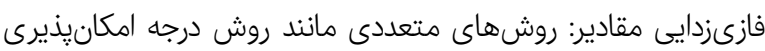

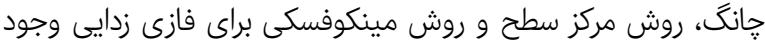
دارد. در اين مطالعه براى فازى زدايى از روش مركز سطح به موني صورت

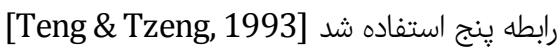
براساس محاسبات فوق بردار ويزه اولويت معيارهاى اصلى به صورت خواهد بود. W $W_{1}=\left[\begin{array}{l}\cdot / \Delta 91 \\ \cdot / r \cdot \mu \\ \cdot / 1 \cdot \Delta\end{array}\right]$

براساس بردار ويزه به دست آمده:

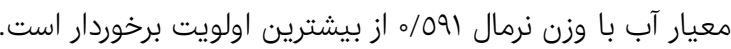

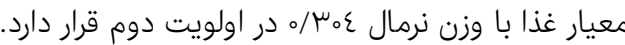

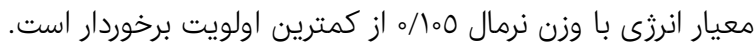

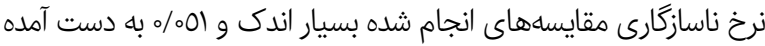

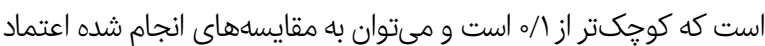

كرد.

مقايسه و تعيين اولويت ززينهها در گام دوم از تكنيك AHP زيرمعيارهاى مربوط به هرئ هر معيار بصورت

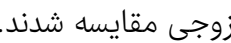

تعيين اولويت ززينهها براساس آب ماتريس مقايسه زوجى گزينهها براساس آب در شكل سم ارايه شده ابه

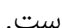

تغييرات بارش در ماههاى فصل زمستان از زانويه تا مارس در سناريو

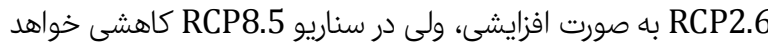
بود و تا •r\% كاهش را تجربه خواهد كرد. در ماههاى فصل بهار، اين دو سناريو تغييرات مشابه خواهند داشت و در شرايط نسبتاً برابر با باهن

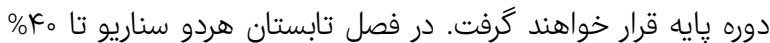
كاهش را تجربه خواهند كرد. در طى فصل ياييز سناريو RCP2.6 تا

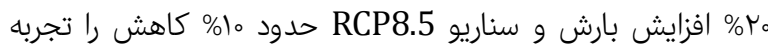
خواهند كرد. با توجه به تغييرات دماى كمينه در هر دو سناريو حداقل

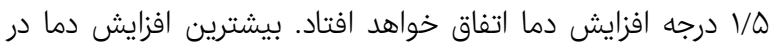

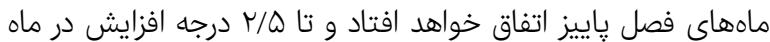

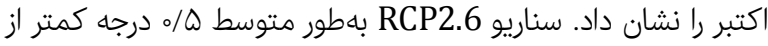
سناريو RCP8.5 افزايش دما را پيشبيشى كرده است. تغييرات دماى داى بيشينه نشاندهنده افزايش حداقل r درجهاي دما در هردو سناريو

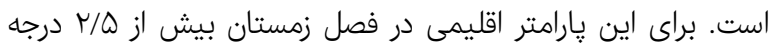

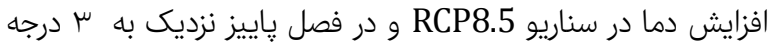
افزايش دما را نشان داد.

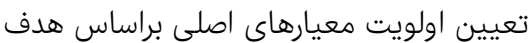

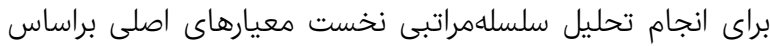
هدف بصورت زوجى مقايسه شدهاند. مقايسه زوجى بسيار ساده لهاه است و تمامى عناصر هر خوشه بايد به صورت دو به دو مقايسه

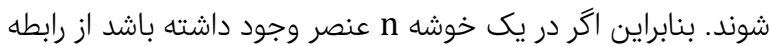
$\frac{n(n-1)}{r}$

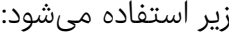
جون سه معيار وجود دارد بنابراين تعداد مقايسههاى انجام شده برابر است با از خبرگان انجام شد. ديدگًاه خبرگان با استفاده از مقياس فازى كمى

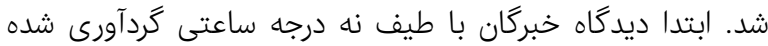

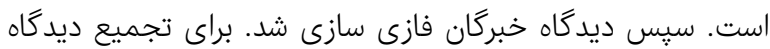

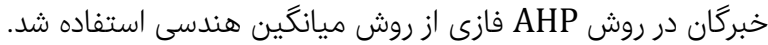

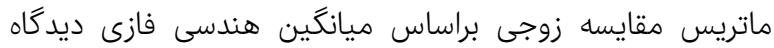

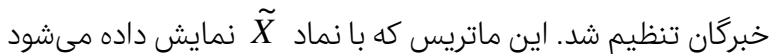
در جدول الارايه شده است.

\begin{tabular}{|c|c|c|c|}
\hline $\mathrm{Cr}$ & $\mathrm{Cr}$ & C) & \\
\hline$(\mu / \mu V, \Psi / \Lambda r, \varepsilon / r o)$ & $(\mu / \varepsilon \mu, \varepsilon, \varepsilon / 7 \mu)$ & $(1,1,1)$ & C) \\
\hline$(r / V \varepsilon, \Psi / \mu I, \Psi / \wedge r)$ & $(1,1,1)$ & $(\circ / T r, \circ / T \omega, \circ / R q)$ & $\mathrm{Cr}^{-}$ \\
\hline$(1,1,1)$ & $(\circ / \mathcal{T}, \circ / \mathcal{}, \circ / \Psi \vee)$ & $(\circ / T K, \circ / T G, \circ / K)$ & س \\
\hline
\end{tabular}

جدول () ماتريس مقايسه زوجى معيارهاى اصلى

يس از تشكيل ماتريس مقايسههاى زوجى به دست آمده، بردار ويزه

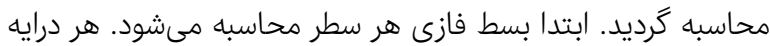


موانع تصميم گيرى در خصوص منابع آب، غذا و انرزى با توجه به تغييرات اقليمى... وجس سيس جمع فازى مجموع عناصر ستون ترجيحات محاسبه ميى خدود:

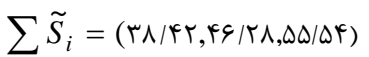

$\left(\sum \tilde{S}_{i}\right)^{-1}=(\cdot / \cdot 11, \cdot / \cdot r r, \cdot / \cdot r \varphi)$

نتايج حاصل از نرمالسازى مقادير به دست آمده به صورت زير

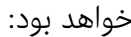

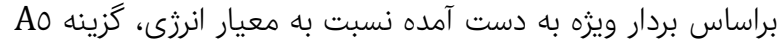

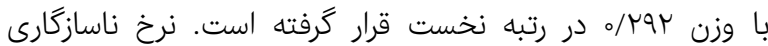
مقايسههاى انجام شده اه/ به دست آمده است كه كوجكتر از // است و مىتوان به مقايسههاى انجام شده اعتماد كرد.

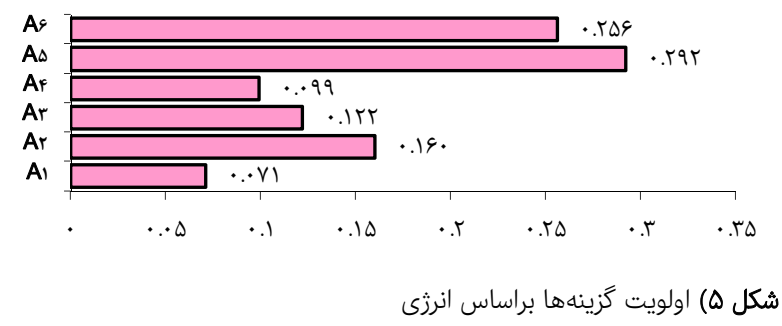

تعيين اولويت نهاييگزينهها

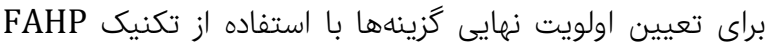

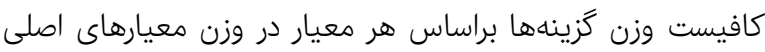

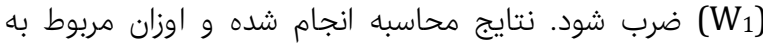
شاخصهاى موردنظر در جدول ه آمده است.

جدول ه) تعيين اولويت نهايى ززينهها با تكنيك FAHP

\begin{tabular}{|c|c|c|c|c|c|c|}
\hline \multirow[b]{2}{*}{ رتبه } & \multirow[b]{2}{*}{ Wt } & $\mathrm{CH}$ & $\mathrm{Cr}$ & C) & معيارها & \multirow[b]{2}{*}{ خزينهها } \\
\hline & &.$/ 1.0$ & $\circ / \mu_{\circ} \varepsilon$ & ./09r & وزن معيارها/موانع & \\
\hline 7 & 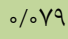 & $\circ / V_{1}$ & .099 &.$\% 79$ & ارتباط و همكارى & A) \\
\hline$\varepsilon$ & $\circ / 1 \varepsilon \varepsilon$ & $\circ / 17 \circ$ & ०/\₹q & o/lmq & تصرآيندهاى & Ar \\
\hline$\mu$ & $\circ / 19 V$ & סR & $\circ / \Lambda \mu$ & $\circ / Y \mid \Lambda$ & فرهنگى ابعاد اجتماعى و & A \\
\hline 0 & $\circ / 1 \circ \Lambda$ & $\circ / .99$ & $\circ / \wedge \vee$ & $\circ / \Lambda Y_{0}$ & شاهيت ياسخ به إى ارتباطى & $A \varepsilon$ \\
\hline 1 & \&/YTI & o/rar & •/Yרו & - TOT & 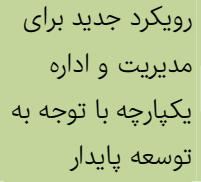 & Ao \\
\hline r & $\circ / M \| 11$ & - TOT & o/ r ro &.$/ 199$ & فناورى و منابع & A\& \\
\hline
\end{tabular}

بنابراين با توجه به محاسبات انجام شده وزن نهايى هريك از

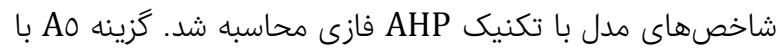

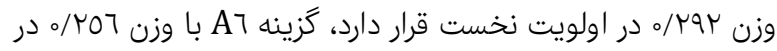

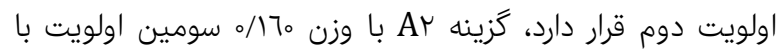

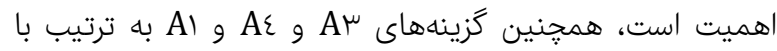

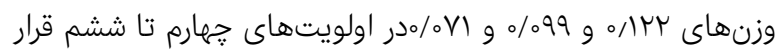

يس از تشكيل ماتريس مقايسههاى زوجى به دست آمده، بردار ويزّه

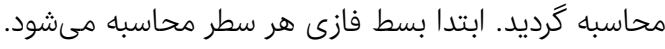

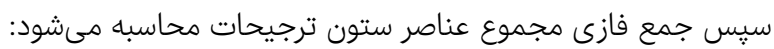
$\sum \tilde{S}_{i}=(r V / r r, F \Delta / \Delta q, \Delta F / q)$

$\left(\sum \tilde{S}_{i}\right)^{-1}=(\cdot / \cdot 1 \Lambda, \cdot / \cdot r, \cdot / \cdot r V)$

نتايج حاصل از نرمالسازى مقادير به دست آمده به صورت زير

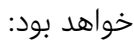

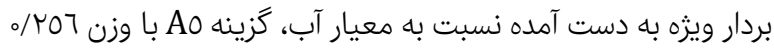

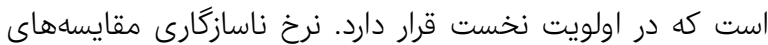

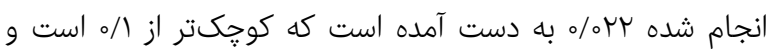
مىتوان به مقايسههاى انجام شده اعتماد كرد.

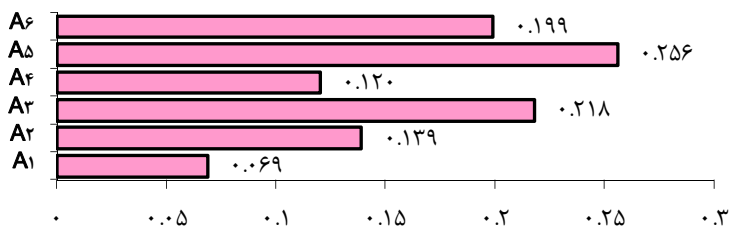

شكل س) اولويت ززينهها براساس آب

تعيين اولويت ززينهها براساس غذا

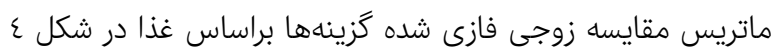
ارايه شده است.

بسط فازى هر سطر محاسبه شد. سيس جمع فازى مجموع عناصر ستون ترجيحات محاسبه مىشود: $\sum \tilde{S}_{i}=(\Psi \% / \Delta Q, Y Y / \Delta T, \Delta / / Q 9)$

$\left(\sum \tilde{S}_{i}\right)^{-1}=(\cdot / \cdot 19, \cdot / \cdot r q, \cdot / \cdot r q)$

نتايج حاصل از نرمالسازى مقادير به دست آمده به صورت زير

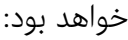

براساس بردار ويزه به دست آمده نسبت به معيار غذا، كَينه A0 با

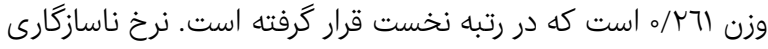

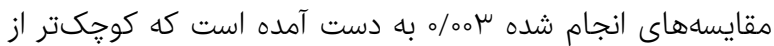
1/ است و مىتوان به مقايسههاى انجام شده اعتماد كرد.

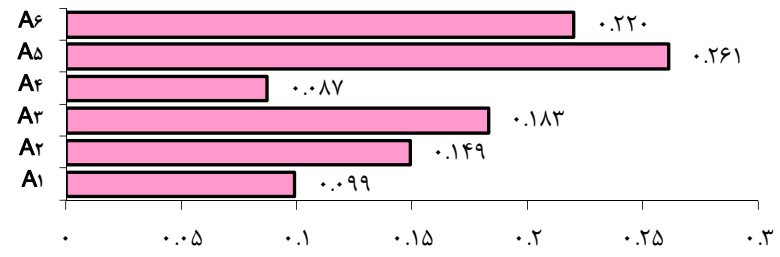
شكل ع) اولويت گزينهها براساس غذا

تعيين اولويت گزينهها براساس انرزى ماتريس مقايسه زوجى فازى شده كزينهها براساس در شكل 0 ارايه

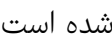
بسط فازى هر سطر محاسبه شد. 
آكًاهى ذينفعان باعث ايجاد سلب اعتماد در جامعه و ايجاد مشكلات

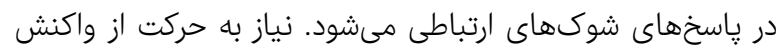

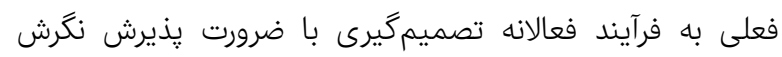

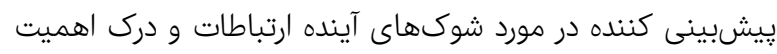

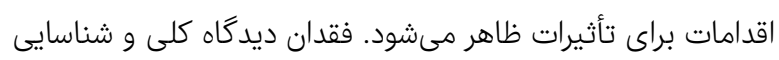
مالكيت و وجود زمانبندى متناقض تحقيق در فعاليتهاى تجارى

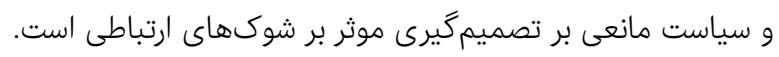

در جدول r موانع مهم تصميمگيرى در ارتباطات آب، غذا و انرزى مدران

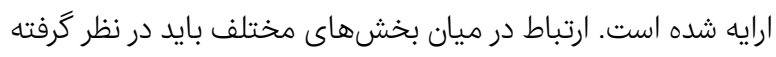

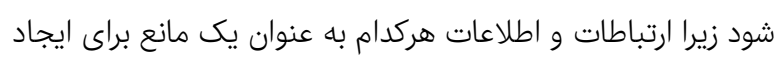

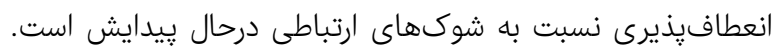

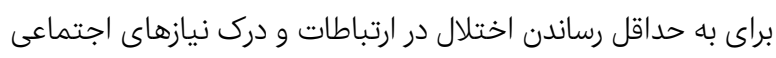

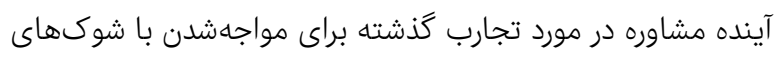

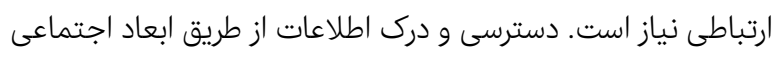

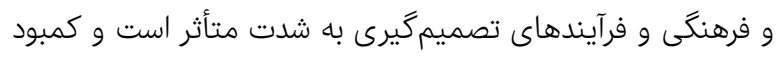

جدول r) ماتريس مقايسه زوجى گزينهها براساس آب

\begin{tabular}{|c|c|c|c|c|c|c|}
\hline A7 & Ao & A $\varepsilon$ & $A^{\mu}$ & Ar & A) & \\
\hline$(\circ / \mathcal{A} V, o / \Delta \xi, o / G V)$ & $\left(0 / T^{\prime}, /{ }^{\prime}, 0 / N\right)$ & $(\circ / \mu \tau, 0 / A 1,0 / \Delta \wedge)$ & 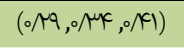 & $(\circ / \mathcal{N} Y, \circ / \mathcal{F}, \circ / \Delta F)$ & $(1,1,1)$ & A) \\
\hline$(0 / \& Y, o / \Lambda F, 1 / \circ F)$ & $(\circ / \wedge Q, \circ / \Delta \mathcal{E}, \circ M)$ & $(0 / 4 \Lambda, 1 / \mu \mu, 1 / 9 \vee)$ & 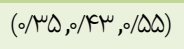 & $(1,1,1)$ & $\left(I N Q, Y / M G, Y N N^{\Psi}\right)$ & Ar \\
\hline$(0 / \wedge \Delta, 1 / 01,1 / \wedge)$ & $\left(\circ / \Delta F, o / N^{\mu}, o / Q \&\right)$ & $(1 / 4 Y, 1 / 99, r / 4 q)$ & $(1,1,1)$ & $(V / A r, r / \mu r, r / A V)$ & $(r / F F, r / A Q, H / F \Delta)$ & $A \mu$ \\
\hline 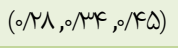 & $(\circ / \mu \mu,, / \mathcal{K}, 0 / \Delta l)$ & $(1,1,1)$ & $(\circ / \mathcal{K}, 0 / Q, 0 / \& \Lambda)$ & $(0 / \xi, 0 / N Q, Y / Y)$ & $(M T, Y / A T, H \wedge K)$ & A $\varepsilon$ \\
\hline$\left(\circ / N^{\top}, \circ / \wedge \Delta, 1 /{ }^{\top}\right)$ & $(1,1,1)$ & $(1 / A \Lambda, Y / F \Lambda, \mu)$ & $(1 / \circ \Delta, 1 / M V, 1 / \Lambda F)$ & $(M \in, M, Y M)$ & 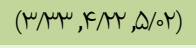 & Ao \\
\hline$(1,1,1)$ & $(0 / 9 \vee, 1 / Y, / / \mu q)$ & $(\Psi / \Psi, T / A T, \Psi / G \Psi)$ & $(\circ / \wedge Q, \circ / 99,1 \wedge \wedge)$ & $(0 / \&, 1 / 9,1 /<q)$ & $(V / \Delta, I / V \Lambda, r / A Q)$ & A7 \\
\hline
\end{tabular}

جدول ץ) ماتريس مقايسه زوجى فازى شده گزينهها براساس غذا

\begin{tabular}{|c|c|c|c|c|c|c|}
\hline A7 & A0 & $A \varepsilon$ & $A^{\mu}$ & Ar & A) & \\
\hline$(0 / \mathcal{A}, 0 / \mathcal{A} \Lambda, 0 / \Delta \Lambda)$ & $(0 / \mu \Psi,, \circ / A, 0 / \Delta Y)$ & $\left(1 /{ }^{\mu}, 1 / M 4, / / \Delta 9\right)$ & $(0 / \mu K, 0 / A Y, 0 / \Delta F)$ & $(\circ / \notin \varepsilon, 0 / \triangle \Lambda, \circ N Q)$ & $(1,1,1)$ & A) \\
\hline$\left(\circ / \triangle Q, \circ / \mathcal{F}^{\circ}, / 9 \Delta\right)$ & $(0 / \mathcal{F}, 0 / \Delta r, 0 / \& \wedge)$ & $(1 / \sim \Lambda, I / G S, r / F)$ & $(0 / 4,0 / N Q, 0 / 9 F)$ & $(1,1,1)$ & $(I / \Upsilon, I N T, Y \wedge S)$ & Ar \\
\hline$(0 / Q, 0 / 94,0 / V)$ & $(0 / \mathbb{F} \Lambda, 0 / \& \mathbb{T}, 0 / \Lambda \mathrm{Q})$ & $(1 / \mathcal{F}, / q \mu, r / \subset \vee)$ & $(1,1,1)$ & 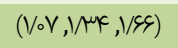 & $(I / V q, Y / \Psi \wedge, Y / A Y)$ & $\mathbf{A \mu}$ \\
\hline$(0 / \mu K, 0 / \propto \mu,, 0 / \Delta F)$ & 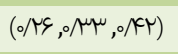 & $(1,1,1)$ & $(0 / K, o / \Delta T, o M)$ & $(0 / \notin q, 0 / \xi, 1 / N \Lambda)$ & $(0 / 9 \mu, o / V Y, o / 9 V)$ & A $\varepsilon$ \\
\hline$(0 / \Lambda, 0 / ৭ \Lambda, 1 / \Gamma)$ & $(1,1,1)$ & $(\Upsilon / \Psi G, \% / \vee \vee, \Psi / \wedge q)$ & $(I / Y, V / / Y, Y, Y M)$ & $(1 /\{\wedge,|/ 91, r / \wedge|)$ & $(V q \mu, Y / \wedge Q, \mu / \Delta)$ & Ao \\
\hline$(1,1,1)$ & $(\circ / \wedge \mu,, / / \curlyvee, 1 / \sim \Delta)$ & $(V / A \Delta, r / \mu, r / A)$ & $\left(1 /{ }^{\mu}, 1 / 91,1 / 99\right)$ & $\left(1 /{ }^{\circ} \Delta, 1 / \sim \mu \Delta, 1 / \Lambda\right)$ & $\left(\mid M^{\mu}, Y / 0 \wedge, r / \Delta l\right)$ & A7 \\
\hline
\end{tabular}

جدول F) ماتريس مقايسه زوجى فازى شده گزينهها براساس انرزى

\begin{tabular}{|c|c|c|c|c|c|c|}
\hline A7 & Ao & $A \varepsilon$ & $A \mu$ & Ar & A) & \\
\hline$(\circ / N F, \circ / N Y, \circ / \mu l)$ & $(0 / T Y, 0 / M Y, 0 / M Y)$ & $\left(\circ / \& Q, \circ / \vee q, 1 / \circ{ }^{\mu}\right)$ & $(0 / K Y, O / \Delta G, O N K)$ & 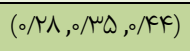 & $(1,1,1)$ & A) \\
\hline$(0 / K, 0 / \Delta 1,0 / \& K)$ & $(0 / \mu r, 0 / k Y, 0 / \Delta K)$ & $(1 / \circ 9,1 / \sim F, 1 / \Delta q)$ & $(0 / q \mu, 1 / \mu, I / / Y)$ & $(1,1,1)$ & $(Y / Y Y, Y / \wedge q, T / \Delta Y)$ & Ar \\
\hline$(0 / \mathcal{F}, 0 / \Delta 1,0 / \& \mu)$ & $(0 / \mu l, o / \mu \Lambda, o / F \Lambda)$ & $(\circ / 9 \Delta, 1 / / 9,1 / \Delta)$ & $(1,1,1)$ & $(\circ / \triangle \wedge, \circ / V Y, 1 / \circ \vee)$ & $(1 / \sim \omega, I / V q, r / 4)$ & $A \mu$ \\
\hline 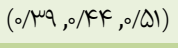 & $(\circ / \mu l, \circ / \Psi \Lambda, \circ / \notin \varphi)$ & $(1,1,1)$ & $(0 / \& \vee, / / \Lambda F, 1 / \circ 9)$ & $(0 / q \mu, \circ / V F, o / A T)$ & $(0 / 9 V, I / T Y, 1 / \Delta K)$ & $A \varepsilon$ \\
\hline$(\circ / N Q, 0 / 9 T, 1 / N F)$ & $(1,1,1)$ & $(Y / \Lambda \Lambda, Y / \& \&, \Psi / M q)$ & $(Y / \diamond V, r / q \Psi, \Psi / Y K)$ & 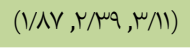 & $(T / Q \mathcal{K}, \Psi / G \Lambda, K / Q)$ & Ao \\
\hline$(1,1,1)$ & $(\circ / \mathcal{M}, 1 / \circ 9,1 / \mu \mu)$ & $(\mathrm{l} /, \textrm{Y} / \mathrm{TV}, \mathrm{Y} / \Delta \Lambda)$ & $(1 / \Delta q, 1 / Q \varepsilon, r / \sim \omega)$ & $(1 / \Delta V, 1 / Q \Lambda, r / F V)$ & $(\Psi / M, \Psi / N, K / \wedge)$ & A7 \\
\hline
\end{tabular}

تفكر يِشبينى نايذير در تأثيرات فورى شوك به ويزه هنگامى كه نه

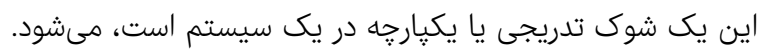

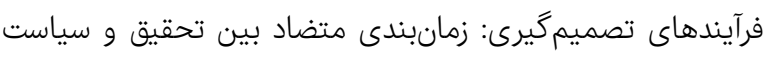

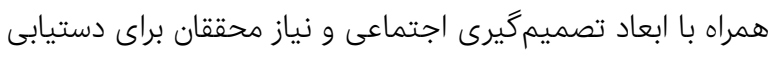

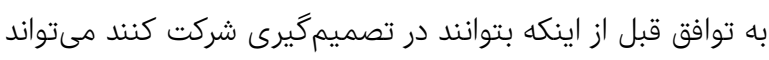

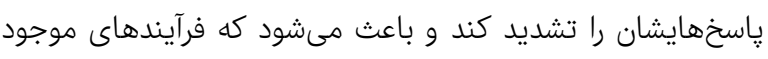
در حال تغيير بيش از حد باشد. نقش يادگيرى و مشكل كلى بـ به

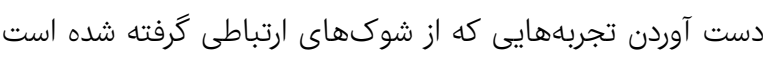
و پاسخها به شدت ظاهر مىشود. به طور خاص نكرانىها در در مورد

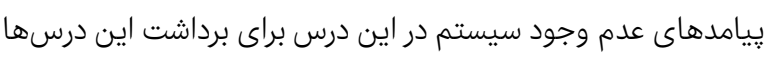

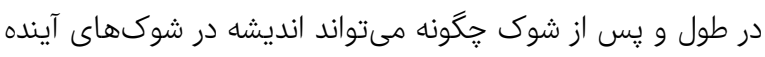

ارتباط و همكارى: ارتباط و همكارى به عنوان ارزشى براى اطمينان

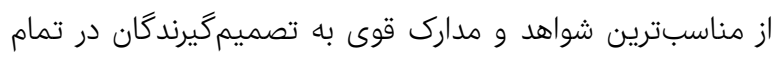

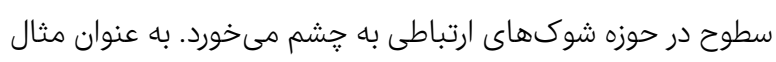

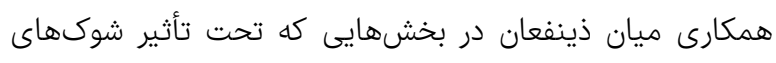

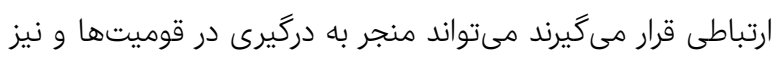

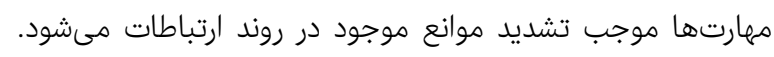

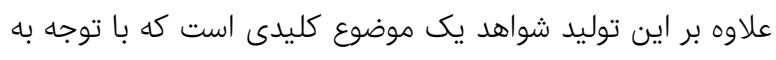

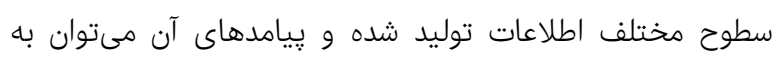
جشم انداز بلند، تصميم گيرى غلط، عدم بررسى دادههاى جايكزين و

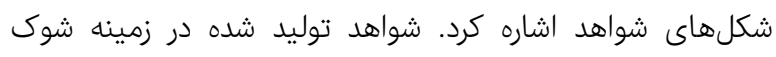
ارتباطى اغلب در واكنش فورى به شوك ايجاد مى شود كه من منجر به 


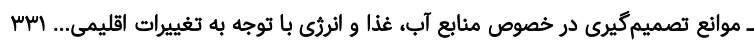

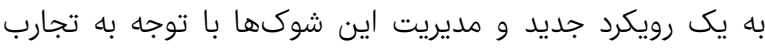

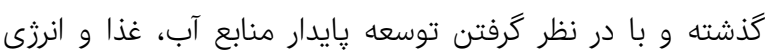
ضرورى است. فناورى و منابع مالى: جالشهاى إن متفاوتى در رابطه با هزينههاى

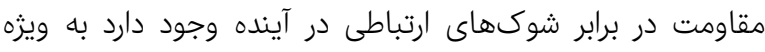

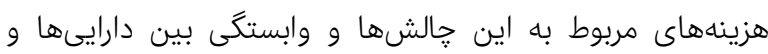

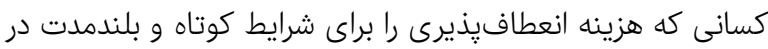

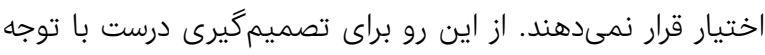
به شوكهاى ارتباطى نياز به فناورىهاى جديد و همجنين رورين منابع

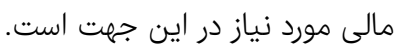

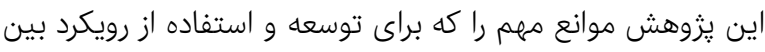

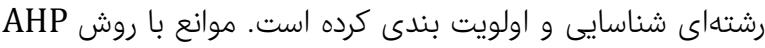

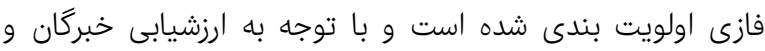

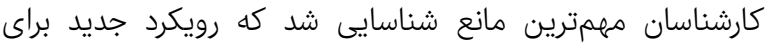

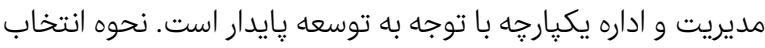
خبركان از بين دانشگاهيان و دولتمردان كه در اين زمينه فعاليت

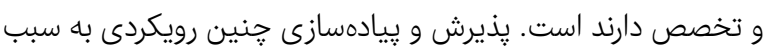
محدوديتهاى اجتماعى يِيجيده است كه در حوزههاى علمى مورد

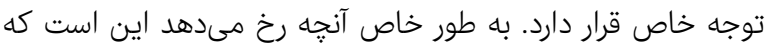
يك رويكرد بين رشتهاى از ارزيابى و تجزيه و تحليل مستلزم دخالت

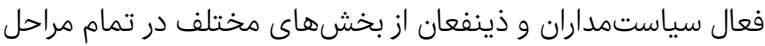

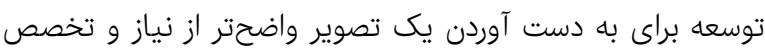

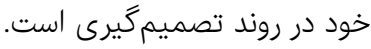

\section{نتيجه گيرى}

منبع آب (وزن نرمال=|Q99/ه) در اولويت نخست، منبع غذا (وزن

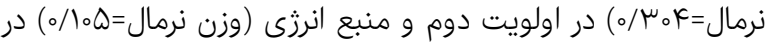

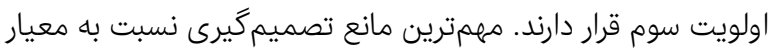

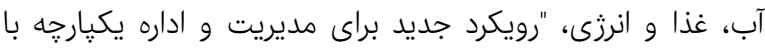

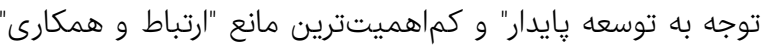

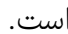

تشكر و قدردانى: صميمانه از همكارى سركار خانم دكتر فاطمه

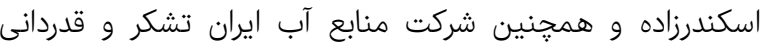

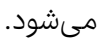

تأييديه اخلاقى: موردى از سوى نويسندكًان گزارش نشده است.

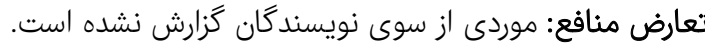

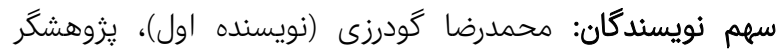

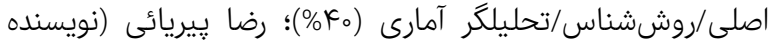
دوم)، نكارنده بحث (هڤ\%)؛ ميررحيم موسوى (نويسنده سوم)،

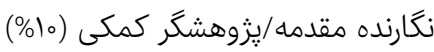
منابع مالى: منابع مالى اين يزوهش تمارئرة مفراً توسط نويسنده دوم (رضا

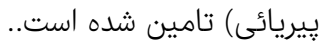

و نحوه يادگيرى اين درسها را به ساير بخش و مقياسها منتقل

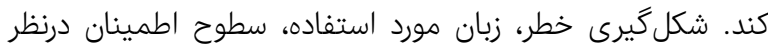

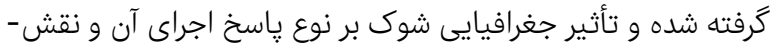

هاى مختلف هدايت در آن تأثير مى گذاردارد.

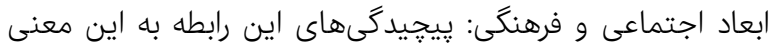

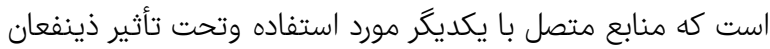
در بخشهاى مختلف است كه هر كدام با فرهنگها، رفتارها، اولويتها و فرآيندهاى مختلف مشخص مختى مشوند. در حالى كه شوكهاى ارتباطى تأثيرات قابل توجهى در جامعه دارند اينها در

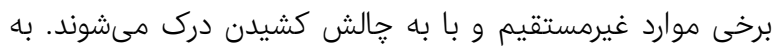

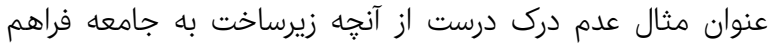

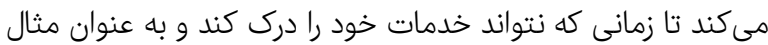

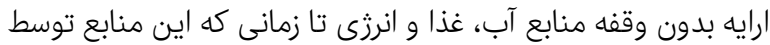

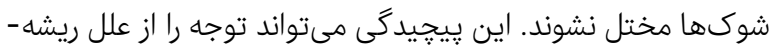

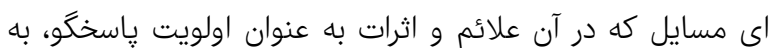
جاى ايجاد فضا براى بازتاب فعال گذشتانكگ برروى سيستم

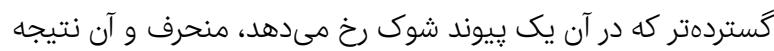

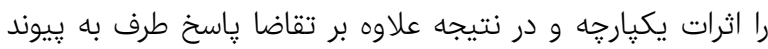

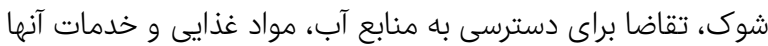

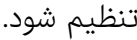
ماهيت پاسخ به شوكهاى ارتباطى: توليد شواهد علمى كه براى

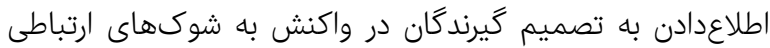
استفاده مىشود نامشخص است و با عدم قطعيت و دائما در حال تكامل است. اين بدين معنى است كه شوكهاى ارتباطى در سطح

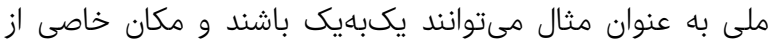

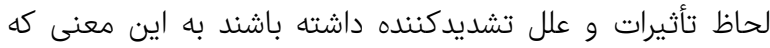
تخصص منابع مىتواند نامن و آسيبذيذيرى را افزايش دهد. جالشهاى متعددى در رابطه با هزينههاى مزاياى مقاومت در برابر

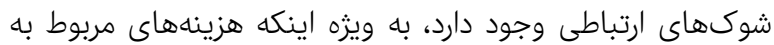

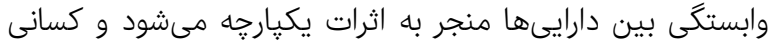

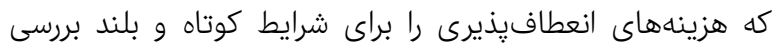
نمىكنند. با توجه به اينكه جُكونكى تغييرات آب و هوايى بهاعنوان

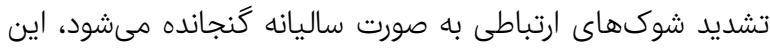

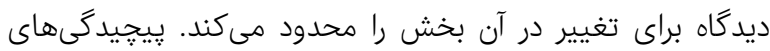

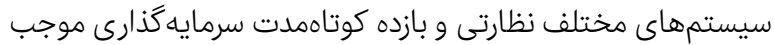

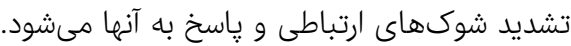
رويكرد جديد براى مديريت و اداره يكيارجه با توجه به توسعه پٍايدار: شواهد ممكن است نياز به تفكر واجراى سريع ايدههاى خلاقانه،

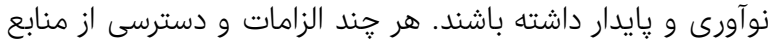

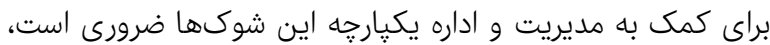
به نظر مىرسد بحث مداوم در سطح جهانى در مورد آنجه در آخر

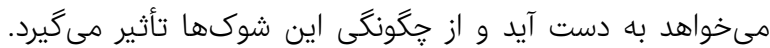

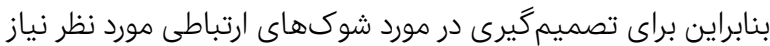


Smith A, et al (2012). Transforming innovation for sustainability. Ecology and Society. 17(2):11.

Lee RD, Mason A, editors (2011). Population aging and the generational economy: A global perspective. Cheltenham: Edward Elgar Publishing.

Meybeck A, Lankoski J, Redfern S, Azzu N, Gitz V, editors (2012). Building resilience for adaptation to climate change in the agriculture sector. Proceedings of a Joint FAO/OECD Workshop. 2012, 23-24 April: Rome.

Millennium Ecosystem Assessment (2005). Ecosystems and human well-being- biodiversity synthesis. Washington, DC: World Resources Institute.

Münchener Rück Stiftung (2012). Natural catastrophes 2011: Analyses, assessments, positions. Munich: MunichRe.

OECD (2012). OECD environmental outlook to 2050: The consequences of inaction. Paris: OECD Publishing.

Philip SA, United Nations Development Programme, United Nations Environment Programme, World Bank, World Resources Institute (2011). Decision making in a changing climate-Adaptation challenges and choices. Washington, DC: World Resources Institute.

Rasul G (2014). Food, water, and energy security in South Asia: A nexus perspective from the Hindu Kush Himalayan region. Environmental Science \& Policy. 39:35-48.

Rasul G, Sharma B (2016). The nexus approach to waterenergy-food security: An option for adaptation to climate change. Climate Policy. 16(6):682-702.

Rees W, Wackernagel M (1996). Urban ecological footprints: Why cities cannot be sustainable-and why they are a key to sustainability. Environmental Impact Assessment Review. 16(4-6):223-248.

Roberts E, Finnegan L (2013). Building Peace around water, land and food: Policy and practice for preventing conflict. Geneva: Quaker United Nations Office.

Smajgl A, Ward J, Pluschke L (2016). The water-foodenergy Nexus-Realising a new paradigm. Journal of Hydrology. 533:533-540.

Smith P, Clark H, Dong H, Elsiddig EA, Haberl H, Harper R, et al (2014). Agriculture, forestry and other land use (AFOLU). In: PCC Working Group III Contribution to AR5. Climate Change 2014: Mitigation of Climate Change. Cambridge: Cambridge University Press.

Teng JY, Tzeng GH (1998). Transportation investment project selection with fuzzy multiobjectives programming. Fuzzy Sets and Systems. 96(3):259-280.

The World Economic Forum Water Initiative (2011). Water security: The water-food-energy-climate nexus. Washington, DC: Island Press.

World Bank Group (2013). Turn down the heat: Climate extremes, regional impacts, and the case for resilience. Washington, DC: World Bank Publications.

World Business Council for Sustainable Development (2014). Co-optimizing Solutions: Water and energy for food, feed and fiber. Geneva: World Business Council for Sustainable Development.

Yumkella KK, Yillia PT (2015). Framing the water-energy nexus for the post-2015 development agenda. Aquatic Procedia. 5:8-12.

Audet R (2014). The double hermeneutic of sustainability transitions. Environmental Innovation and Societal Transitions. 11:46-49.

Biggs EM, Bruce E, Boruff B, Duncan JMA, Horsley J, Pauli $\mathrm{N}$, et al (2015). Sustainable development and the waterenergy-food nexus: A perspective on livelihoods. Environmental Science \& Policy. 54:389-397.

Cai X, Wallington K, Shafiee-Jood M, Marston L (2018). Understanding and managing the food-energy-water nexus-opportunities for water resources research. Advances in Water Resources. 111:259-273.

Ely A, Smith A, Stirling A, Leach M, Scoones I (2013). Innovation politics post-Rio+20: Hybrid pathways to sustainability? Environment and Planning C: Politics and Space. 31(6):1063-1081.

Endo A, Tsurita I, Burnett K, Orencio PM (2017). A review of the current state of research on the water, energy, and food nexus. Journal of Hydrology: Regional Studies. 11:2030.

Hallegatte S, Bangalore M, Bonzanigo L, Fay M, Kane T, Narloch U, et al (2015). Shock waves: Managing the impacts of climate change on poverty. Washington, DC: World Bank Publications.

Hoff $\mathrm{H}$ (2011). Understanding the nexus. Background paper for the Bonn 2011 Nexus Conference: The Water, Energy and Food Security Nexus. 2011,16-18 November: Stockholm.

Howarth C, Monasterolo I (2016). Understanding barriers to decision making in the UK energy-food-water nexus: The added value of interdisciplinary approaches. Environmental Science \& Policy. 61:53-60.

Hsiang SM, Meng KC, Cane MA (2011). Civil conflicts are associated with the global climate. Nature. 476:438-441.

Hussey K, Pittock J (2012). The energy-water nexus: Managing the links between energy and water for a sustainable future. Ecology and Society. 17(1).

International Energy Agency (2011). World energy outlook 2011. Paris: International Energy Agency.

Intergovernmental Panel on Climate Change (2014). Climate change 2014: Synthesis report: Longer report. Geneva: Intergovernmental Panel on Climate Change.

Kahraman C, editor (2008). Fuzzy multi-criteria decision making: Theory and applications with recent developments. $16^{\text {th }}$ ed . Berlin: Springer.

Kelley C, Mohtadi Sh, Cane MA, Seager R, Kushnir Y (2015). Climate change in the Fertile Crescent and implications of the recent Syrian drought. Proceedings of the National Academy of Sciences of The United States of America (PNAS). 112(11):3241-3246.

Kurian M, Ardakanian R (2014). Institutional arrangements and goverance structures that advance the nexus approach to management of environmental resources. In: Hülsmann S, Ardakanian R, editors. White Book on Advancing a Nexus Approach to the Sustainable Management of Water. Soil and Waste. Dresden: UNUFLORES.

Leach M, Rockström J, Raskin P, Scoones I, Stirling AC, 